\title{
Retailer and Manufacturer Advertising Scheduling in a Marketing Channel ${ }^{\text {th }}$
}

\author{
Guiomar Martín-Herrán ${ }^{1, *}$, Simon P. Sigué2,**
}

\begin{abstract}
Despite the fact that the use of sporadic advertising schedules is well established in both the advertising literature and market place, the marketing channel literature that focuses on vertical interactions has consistently prescribed continuous advertising strategies over time. This paper investigates, in a bilateral monopoly context a situation in which a manufacturer and a retailer control their pricing and advertising decisions, the optimal scheduling of advertising in a planning horizon of three periods. We found that, consistent with the advertising literature, the integrated channel adopts pulsing to benefit from advertising positive carryover effects. Conversely, when pricing and advertising decisions are uncoordinated, channel members can optimally implement each of the following three advertising schedules. The full continuous schedule where channel members advertise in the three periods. The full pulsing schedule in which the two channel members advertise only in the first and third periods. The mix schedule where the retailer advertises in the three periods and the manufacturer advertises exclusively in the first and third periods. Depending on the magnitude of the long-term effects of retailer and manufacturer advertising, each of the three schedules can be implemented.
\end{abstract}

Keywords: Advertising scheduling. Manufacturer advertising. Marketing channel. Pric-

\footnotetext{
« The first author's research is partially supported by MEC under project ECO2014-52343-P, cofinanced by FEDER funds and the COST Action IS1104 "The EU in the new economic complex geography: models, tools and policy evaluation".

*Departamento de Economía Aplicada (Matemáticas), Universidad de Valladolid, Avda. Valle de Esgueva, 6, 47011, Valladolid, Spain. Tel.: +34 983423330 Fax: +34 983 423299; E-mail: guiomar@eco.uva.es

** Corresponding author: Faculty of Business, Athabasca University, 201-13220 St. Albert Trail, Edmonton, AB, T5L 4W1, Canada. Tel.: 780460 0340, E-mail: simons@athabascau.ca

${ }^{1}$ IMUVA, Universidad de Valladolid

${ }^{2}$ Faculty of Business, Athabasca University (Canada)
} 
ing. Pulsing. Retailer advertising.

\section{Introduction}

The growing fragmentation of the media and the continuous increase in marketing communication costs are constantly challenging marketing managers to improve the effectiveness of their marketing communication programs. One of the major challenges that manufacturers and retailers encounter in marketing channels is how to optimally schedule their respective investments in advertising programs over time.

Retailer advertising, also known as local advertising, refers to advertising or promotional activities undertaken by retailers to locally promote manufacturers' products. It contributes to the effectiveness of advertising in marketing channels in three major ways. First, retailers have a better knowledge of their local markets and can therefore undertake more effective advertising programs for manufacturers' products. Second, retailers use local media, which generally apply lower advertising rates than national media. Finally, retailer advertising is believed to stimulate immediate sales at the retail level, although its long-term effects on sales remain controversial (Jørgensen et al., 2000, 2003; Herrington and Dempsey, 2005).

Manufacturer advertising or national advertising are advertising activities initiated and controlled by a manufacturer to promote their own products that have a nationwide scope. Expenditures on this type of advertising represent a significant portion of marketing budgets in many companies. For instance, according to Kantar Media's index, Procter \& Gamble, AT\&T, General Motors (GM), Verizon, and L'Oréal spent \$2.95, \$1.9, \$1.78, $\$ 1.64$, and $\$ 1.34$ billion, respectively, on advertising in 2011. These same companies also spent $\$ 773.8, \$ 535.5, \$ 593.4, \$ 342.4$, and $\$ 342.4$ million on national advertising programs in the first quarter of 2014. Manufacturer advertising tends to have a variety of objectives, including promoting product awareness, brand image, brand preference, and product purchase. Depending on the objective of a specific manufacturer advertising campaign,

its effects on both short- and long-term sales can vary considerably (Herrington and Dempsey, 2005).

Casual observations of advertising practices in some industries indicate that there are 
periods when both manufacturer and retailer advertising expenditures reach their maxima; while in others, advertising expenditures are substantially reduced, often reaching zero. This is the case of the automobile industry, where the emphasis of marketing communication activities significantly changes over months and both dealers and manufacturers spend substantial amounts on advertising. In summer and early fall, manufacturers and dealers focus on stimulating the sales of the current year's models. Around the end of fall and beginning of winter, while dealers still run some promotional activities, manufacturers generally shift their focus to advertising programs that communicate the distinctive features of the next year's models. Kantar Media (2014) attributes the drop of $5.8 \%$ of local newspaper advertising in the first quarter of 2014 to auto dealers' cutbacks in local advertising. Conversely, at the same period, manufacturers such as General Motors, Fiat Spa, and Toyota Motor significantly saw dramatic increases of 55.8\%, 38.8\%, and 17.7\%, respectively in their advertising expenditures. The launches of these manufacturers' 2014 redesigned car models where the main drivers of the increases observed in manufacturers' advertising expenditures.

Very little has been done in the marketing channel literature to formally investigate the simultaneous optimal scheduling of retailer and manufacturer advertising programs. Channel research that incorporates advertising has mainly focused on cooperative advertising, as a mechanism that can help to either coordinate channels or improve channel efficiency (see Aust and Buscher (2014) and Jørgensen and Zaccour (2014) for reviews). A significant portion of the published works uses static games and, therefore, overlooks the impact of channel members' advertising decisions over time (e.g., Karray, 2013; Karray and Zaccour, 2006; Szmerekovsky and Zhang, 2009; Xie and Ai, 2006; Yan, 2010). Those that use differential games capture the impact of channel members' advertising decisions over time, but many prescribe constant advertising strategies over time or advertising strategies that depend on the evolution of the goodwill of manufacturers' brands (e.g., Jørgensen et al., 2001, 2003; Sigué and Chintagunta, 2009; Zhang et al., 2013). Retailers and manufacturers are given the opportunity to adjust their advertising expenditures as the goodwill stocks of manufacturers' products evolve, generally, to converge toward a steady state. In either case, while the study of the optimal advertising scheduling is not 
their main goal, current advertising works in the marketing channel literature prescribe continuous advertising program schedules and cannot explain the use of discontinuous advertising schedules observed in the market place. The first formal attempt to investigate retailer advertising and cooperative advertising scheduling in a bilateral monopoly uses a two-period game (Martín-Herrán and Sigué, 2017). This paper shows that the retailer may delay advertising to the second period when advertising either has minimal impact on short-term sales or harms long-term sales. Otherwise, the retailer should continuously advertise with or without a cooperative advertising support from the manufacturer.

Advertising scheduling has, however, been extensively studied both theoretically and empirically in the marketing literature (e.g., Dubé et al., 2005; Freimer and Horsky, 2012; Mahajan and Muller, 1986; Mesak and Ellis, 2009; Sasieni, 1989; Villas-Boas, 1993). Among other issues, researchers have investigated factors that favor the use of either advertising pulsing schedules or other alternatives such as continuous or even advertising schedules. In an advertising pulsing schedule, the advertiser alternates between high and zero levels of advertising, while in a continuous or even advertising schedule, the firm advertises without interruption or at a constant level throughout the planning period (as in all current dynamic channel models using the Nerlove Arrow's goodwill accumulation model). Sales response to advertising and the existence of advertising carryover effects on future demands are generally identified as the main explanations of the superiority of pulsing advertising. In particular, it is believed that pulsing is optimal under the Sshaped advertising response curve, which captures both the phenomena of increasing and decreasing marginal returns to various levels of advertising efforts (Mahajan and Muller, 1986; Sasieni, 1989; Villas-Boas, 1993). Pulsing is also considered a better cost-saving advertising practice, compared to other scheduling alternatives, when advertising effects decay slowly over time (Ephron and McDonald, 2002; Dubé et al., 2005). Advertisers can take advantage of the carryover effect and temporally stop their advertising activities as a way of reducing advertising costs (Aravindakshan and Naik, 2011). This well-established theory in the monopoly has not been formally assessed in a marketing channel context. The recent work by Martín-Herrán and Sigué (2017), in addition to focusing on cooperative advertising, is limited to two periods, and cannot therefore qualify as studying 
pulsing as defined in this literature. On the other hand, some marketing textbooks tend to exclusively link advertising scheduling to product uses. For instance, continuous advertising schedules are believed to be suitable for products that are used on a sustained basis regardless of the season (e.g., Belch et al., 2014).

This paper extends for the first time previous research on advertising scheduling to a two-member marketing channel, in which a manufacturer and a retailer have the possibility to undertake their own advertising programs in a three-period planning horizon. Allowing the manufacturer and retailer to advertise simultaneously, as we do in this research, creates two major issues in marketing channels that can change our current knowledge base of advertising scheduling. The first is the opportunism between channel partners due to the fact that they both make separate advertising decisions that affect the demand of the product. As a consequence, a channel member may not invest in advertising or the two channel members may underinvest in advertising compared to the optimal levels of an integrated channel. In such a context, pulsing can easily be motivated by the desire to reduce advertising costs at the expense of a channel partner. Also, lower advertising expenditures due to free-riding may favor continuous advertising schedules, as prescribed in the current channel literature. The second is the controversy about the role of advertising in market development. While it is commonly argued that the retailer invests in advertising to boost sales in the short run, the now well-established existence of long-term effects of retailer advertising activities change channel interactions. For instance, some retailer advertising activities are believed to decrease brand preference and quality perception and to increase price sensitivity at the retail level in the long run (DelVecchio et al. 2006). This belief has led manufacturers like Toyota and Honda to proscribe advertising that features prices below invoice to their dealers (Barkholz, 2015). In many cases, manufacturers are not able to prevent retailers from undertaking the type of advertising that best satisfies their various goals, including clearing unwanted stocks and maximizing sales in some specific periods. They can however schedule their own advertising to either counterbalance or support the effects of any advertising activities that retailers may want to undertake. The question in a bilateral monopoly then is: How should the manufacturer and retailer, who are given the possibility to advertise throughout a planning horizon 
of three periods, optimally schedule their respective advertising activities? Particularly, should channel members adopt a full pulsing schedule, a full continuous schedule, or a mixed schedule?

The full pulsing schedule in this configuration consists of simultaneously undertaking both retailer and manufacturer advertising in the first and third periods, while a complete advertising break is taken in the second period by the two channel members. The full continuous schedule refers to spreading both retailer and manufacturer advertising efforts over the three periods. A mix schedule refers to a situation where either the manufacturer or the retailer takes an advertising break in the second period (but not both at the same time) and the two channel members advertise in the first and third periods.

To address the above issues, we confine our interest to a case where a manufacturer sells a single brand to a retailer. We develop a stylized three-period model to capture the carryover and decay effects of the two types of advertising. Examples of the automobile industry are used throughout, but any other industry (e.g., household appliances, telecommunications, office supplies, and technical equipment) that maintains a sustained level of demand during the planning period would serve. In each period, the manufacturer sets a wholesale price and its own advertising level, while the retailer determines a retail price and its own advertising level. We study both the case of a coordinated and uncoordinated channel. In an uncoordinated channel, the Stackelberg equilibrium concept is used, assigning, on an ad hoc basis, the leader role to the manufacturer. Three feasible advertising schedules, including the full pulsing schedule, full continuous schedule, and mixed schedule (the manufacturer takes the second-period advertising break alone), as described above, are endogenously identified and their strategies and profits are compared.

We hope the findings of this research will shed some theoretical light on advertising scheduling issues in marketing channels. Particularly, we expect them to enhance our understanding of the impact of vertical interactions on advertising scheduling. These findings should also be useful to marketing managers, as they will help not only to coordinate advertising programs over time, but also to realize the consequences of the long-term effects of their advertising decisions.

The remainder of the paper is organized as follows. Section 2 describes the model 
and discusses its assumptions. Section 3 provides the optimal advertising schedule of the integrated channel. Section 4 derives three equilibrium solutions for the uncoordinated channel and investigates the conditions under which these equilibria can be implemented. Section 5 compares the strategies of the integrated and uncoordinated channels. Finally, Section 6 concludes and discusses the managerial and theoretical implications of our findings.

\section{The model}

Consider a two-member channel in which a manufacturer sells a product to a retailer, who then sells it to consumers. The two channel members operate in a market in which competition is of no consequence at either the manufacturing or retail levels. This assumption, which is in line with several other bilateral monopoly models in the marketing channel literature, helps to focus on the impact of vertical strategic interactions between channel partners on advertising scheduling decisions. These vertical interactions exist even if channel members face competition, but they have, surprisingly, been overlooked in the current literature, which has, instead, exclusively investigated horizontal interactions (e.g., Freimer and Horsky, 2012; Villas-Boas, 1993).

Let $a_{i}$ and $A_{i}$ represent respectively the rates of retailer and manufacturer advertising in period $i, i \in\{1,2,3\}$. Let $w_{i}$ and $p_{i}$ denote, respectively, the wholesale and retail prices in period $i$. We specify in Table 1 a model that describes the manufacturer's and retailer's pricing and advertising strategic interactions over a three-period planning horizon. This horizon is chosen to study advertising scenarios that are consistent with the established definition of pulsing and to demonstrate that after an initial investment in advertising, a channel member may stop and resume investments in subsequent periods. The length of each period and the duration of the planning horizon are exogenously set. This model can apply to various products, including cars, refrigerators, and TV sets that are sold continuously throughout the year. Conversely, this model does not fit well with seasonal products, such as snow skis and winter clothing. There is no advertising for this type of products at some periods, mainly because of the lack of demand. Advertising carryover, which is one of the key ingredients of the theory developed in this paper, does not directly 
influence the decision to stop advertising in such a context.

(Insert Table 1 about here)

The retailer sets the rate of advertising $\left(a_{i}\right)$ and a retail price $\left(p_{i}\right)$, while the manufacturer determines the rate of advertising $\left(A_{i}\right)$ and a wholesale price $\left(w_{i}\right)$ in each period $i, i \in\{1,2,3\}$. For convenience and tractability, we assume the following linear demand functions: $q_{1}=g-p_{1}+\delta a_{1}+\alpha A_{1}, q_{2}=g-p_{2}+\delta^{2} a_{1}+\alpha^{2} A_{1}+\delta a_{2}+\alpha A_{2}$, and $q_{3}=g-p_{3}+\delta^{3} a_{1}+\alpha^{3} A_{1}+\delta^{2} a_{2}+\alpha^{2} A_{2}+\delta a_{3}+\alpha A_{3}$. The use of linear demand functions is common in marketing channel literature (e.g., Martín-Herrán et al., 2010; Sigué, 2008). The subscripts represent the first, second, and third periods, $g$ accounts for the baseline demand, $\delta$ and $\alpha$ stand for the effects of retailer and manufacturer advertising. The effectiveness of retail prices in all three periods is set to 1 for convenience, while retailer and manufacturer advertising effects always lie between 0 and 1 in the current period and decrease exponentially in subsequent periods. For instance, the effect of the first-period retailer advertising are respectively, $\delta, \delta^{2}$, and $\delta^{3}$ in the first, second, and third periods. This specification captures the well-known decay effect of advertising (Jørgensen et al., 2001). The idea is that channel members cannot continuously rely on past advertising investments to grow or sustain sales. Indeed, Aravindakshan and Naik (2011) report that in the milk industry, when advertising is stopped, sales can remain steady for a year and then drastically decline. Also, we consider that the current effects of advertising do not change from one period to another.

We do not make any restrictive assumption on the relative importance of the effects of both retailer and manufacturer advertising. Obviously, the relative effectiveness of both retailer and manufacturer advertising may depend on several exogenous factors, such as the nature and content of the advertisements and the credibility of the medias used, which we do not capture in this study (Breuer et al., 2011).

Observe that the effective baseline demands in periods 2 and 3 respectively are: $g+$ $\delta^{2} a_{1}+\alpha^{2} A_{1}$ and $g+\delta^{3} a_{1}+\alpha^{3} A_{1}+\delta^{2} a_{2}+\alpha^{2} A_{2}$. Advertising in previous periods contributes to expanding the current market base either by attracting new customers or by increasing the consumption of existing customers. On the other hand, previous prices do not affect 
current demand. In other words, consumers do not remember prices paid in previous periods or use them as references or expected prices in the current period.

Retailer advertising and manufacturer advertising costs are convex and represented, respectively, by $\frac{1}{2} a_{i}^{2}$ and $\frac{1}{2} A_{i}^{2}$. Convex costs are a standard assumption in the literature when advertising decision variables enter the demand functions linearly. They mean that the marginal costs of advertising or promotional activities are increasing (Aust and Buscher, 2014).

Without loss of generality, we set the production and other administrative costs to zero. The retailer's and manufacturer's unit margins are respectively: $p_{i}-w_{i}$ and $w_{i}$, $i \in\{1,2,3\}$. The retailer's $\left(R_{i}\right)$ and manufacturer's $\left(M_{i}\right)$ profits in period $i, i \in\{1,2,3\}$, are given by

$$
\begin{array}{lll}
R_{1}=\left(p_{1}-w_{1}\right) q_{1}-\frac{1}{2} a_{1}^{2}, & R_{2}=\left(p_{2}-w_{2}\right) q_{2}-\frac{1}{2} a_{2}^{2}, & R_{3}=\left(p_{3}-w_{3}\right) q_{3}-\frac{1}{2} a_{3}^{2}, \\
M_{1}=w_{1} q_{1}-\frac{1}{2} A_{1}^{2}, & M_{2}=w_{2} q_{2}-\frac{1}{2} A_{2}^{2}, & M_{3}=w_{3} q_{3}-\frac{1}{2} A_{3}^{2} .
\end{array}
$$

The manufacturer's and retailer's main problems are to maximize their respective profits over the three periods: $M=M_{1}+t_{M} M_{2}+t_{M}^{2} M_{3}$ and $R=R_{1}+t_{R} R_{2}+t_{R}^{2} R_{3}$, where $t_{M}$ and $t_{R}$ are the manufacturer's and retailer's discount factors. For simplicity, hereafter, we normalize these discount factors to $1\left(t_{M}=t_{R}=1\right)$. The use of a common discount rate for channel members is typical in the literature. It is based on the belief that in a situation of bilateral monopoly in which the retailer only sells the manufacturer's product, the two channel members have the same interest in future profits. In addition, in the current context of very low interest rates, channel members do not heavily discount future profits.

\section{Vertically integrated channel}

The aim of this section is to identify which advertising schedule a perfectly coordinated channel will adopt. The manufacturer and retailer come together to set, in each period $i$, the retail price $p_{i}$ and their respective advertising rates $A_{i}$ and $a_{i}$ so as to maximize their joint profits over the three periods: $T=\sum_{i=1}^{3} T_{i}$. The integrated channel profit function in period $i$ is as follows: $T_{i}=M_{i}+R_{i}=p_{i} q_{i}-\frac{1}{2} a_{i}^{2}-\frac{1}{2} A_{i}^{2}, i \in\{1,2,3\}$. 
The integrated channel solves backwards a simple optimization problem. In Stage 3, the decision marker sets $A_{3}, a_{3}$, and $p_{3}$ to maximize the third-period joint profit, $T_{3}$. In Stage 2, the optimal third-period decisions are incorporated into the second-period joint profit, $T_{2}$, and the optimal second-period decisions are subsequently derived. Finally, the second-period optimal decisions are incorporated into the joint profit function in Stage 1, $T_{1}$, to derive the optimal first-period decisions.

The derivation of the optimal strategies for the integrated channel is provided in Appendix A. Proposition 1 below summarizes the main finding.

Proposition 1. The integrated channel finds it optimal to continuously conduct both retailer and manufacturer advertising during the three-period planning horizon.

Proposition 1 supports the view that the integrated channel adopts the full continuous schedule, in which, the two types of advertising are undertaken from the first to third period. An analysis of the feasibility conditions helps to better understand this optimal solution. The optimal decisions and profits derived in Appendix A all depend on the two major parameters of the model, $\delta$ and $\alpha$. As a result, some conditions need to be imposed on these parameters to obtain non-negative profits, positive pricing decisions in the three periods, positive advertising decisions in the first period, and non-negative advertising decisions in the second and third periods.

Non-negative profits are required to ensure that channel members, at least, can breakeven. The requirement of positive pricing decisions is obvious. Also, the requirement to have non-negative advertising in the second and third periods is consistent with the business practice, as advertising may or may not be undertaken. On the other hand, we require the first-period advertising decisions to be positive $\left(a_{1}>0, A_{1}>0\right)$ to reduce the number of possible advertising schedules and to allow us to focus on those that can potentially meet our definition of full pulsing. Therefore, schedules in which either both advertising decisions are zero, or any one of them is zero, in the first period are excluded from our analysis. This is necessary to demonstrate that after an initial investment in the two types of advertising, the integrated channel may find it optimal to stop and resume advertising in subsequent periods. Numerical simulations were carried out using 
Mathematica 10.0.2.0. to identify the feasibility conditions of the finding in Proposition 1 for different values of $\delta$ and $\alpha$. Figure 1 below displays these conditions.

(Insert Figure 1 about here)

Figure 1 shows that the finding in Proposition 1 holds only when the current effects of either type of advertising are not extremely large. This also implies that the carry-over effects of retailer and manufacturer advertising in subsequent periods are relatively small, as they exponentially decrease over time. Thus, because the two types of advertising do not stimulate current sales highly and their long-term effects are even smaller, the integrated channel cannot afford to stop any of the two types of advertising at any time. Any advertising break in a given subsequent period will negatively impact on the integrated channel sales as the carryover effects of previous advertising are not high enough to compensate for the break.

Alternatively, when the current effects of either type of advertising are extremely high, the finding in Proposition 1 does not hold, as illustrated in the unfeasible (UF) region in Figure 1. In this specific region, some of the feasibility conditions discussed above are not met. For instance, retailer and manufacturer advertising cannot be undertaken simultaneously in the first period. The integrated channel finds it optimal to undertake only one of the two types of advertising in the first period to maximize its profits. The carryover effects of very impactful retailer and manufacturer advertising still decrease exponentially in such a context, but they are relatively important, especially in the second period, as the current effects of advertising are high. This also opens the door for the adoption of pulsing schedules to benefit from substantial positive carryover effects.

\section{Uncoordinated channel}

In this section, channel members maximize their individual profits. The Stackelberg equilibrium concept is used to derive equilibria for the model. The manufacturer and retailer are, respectively, the Stackelberg leader and follower. The sequence of the moves of the two players is as follows. The manufacturer announces his first-period decisions in 
Stage 1. The retailer reacts to the manufacturer's announcement in Stage 2 to determine her optimal first-period strategies. Subsequently, the manufacturer announces his secondperiod decisions in Stage 3, which is followed by the reaction of the retailer in Stage 4 as she determines her optimal second-period retail price and advertising rate. Finally, the manufacturer announces his third-period decisions in Stage 5, and the retailer reacts to this announcement in Stage 6. In such a configuration, subgame-perfect equilibria are obtained by deriving optimal solutions backwards. Essentially, the retailer's optimal third-period strategies in Stage 6 are obtained first. Second, the manufacturer's optimal third-period decisions in Stage 5 are derived after the introduction of the retailer's optimal third-period decisions into the manufacturer's problem. Third, the optimal strategies of Stages 5 and 6 are incorporated into the retailer's second-period problem in Stage 4 to derive the retailer's optimal strategies of the period. Fourth, the manufacturer's optimal second-period decisions in Stage 3 are derived after the introduction of the retailer's optimal second-period decisions into the manufacturer's problem. Fifth, the optimal strategies of Stages 3 and 4 are incorporated into the retailer's first-period problem in Stage 2 to derive the retailer's optimal strategies of the period. Lastly, the manufacturer's first-period problem in Stage 1 is solved knowing the strategies of the previous stages.

The derivation of the equilibrium solution for the uncoordinated channel is detailed in Appendix B. As in the case of the integrated channel, we assume that the first-period retailer and manufacturer advertising are positive $\left(a_{1}>0, A_{1}>0\right)$. This allows us to rule out scenarios in which one of the two types of advertising is not undertaken in the first period. Proposition 2 presents the optimal advertising schedules at the equilibrium.

Proposition 2. At the equilibrium, the manufacturer and retailer can adopt any of the three advertising schedules in Table 2 below, referred to as Scenarios FC, FP, and M.

(Insert Table 2 about here)

Scenario FC (Full Continuous) corresponds to the situation where the two channel members adopt continuous advertising schedules. Scenario FP (Full Pulsing) is optimal when the two channel members adopt pulsing schedules. Scenario M (Mixed) refers to the 
situation where the manufacturer adopts a pulsing schedule and the retailer continuously advertises. It is demonstrated in Appendix B that the case where the manufacturer continuously advertises and the retailer adopts a pulsing schedule is unfeasible. Again, some restrictions need to be imposed on parameters $\delta$ and $\alpha$ to meet the conditions on strategies and profits. Using numerical simulations, we identify and display in Figure 2, the conditions under which the three scenarios in Proposition 2 are feasible.

(Insert Figure 2 about here)

Figure 2 is divided into four areas. In the upper area of the figure, denoted by $U F$, the three advertising schedules are unfeasible. In this area, regardless of the value of the current effect (carryover effect) of the manufacturer advertising, retailer advertising is highly impactful both in the short and long terms. In such a context, the retailer increases advertising expenditures to levels that are not economically sustainable for the channel. As a consequence, some of the conditions on channel members' strategies and profits necessary to ensure healthy business cannot be met.

Conversely, the three scenarios are feasible in the area at the bottom of Figure 2. In this area, the current effect of retailer advertising cannot exceed 0.7, while the current effect of the manufacturer advertising can take any value between 0 and 1, depending on the current effect of retailer advertising. For instance, manufacturer advertising can reach its maximum effect when retailer advertising does not significantly impact on sales. Because the retailer does not have a direct incentive to heavily advertise in this area, retail prices remain under control regardless of the advertising schedule adopted, allowing all channel members to, at least, break even.

Between these two extremes, there are two other areas. In the area just below the upper area, only the full pulsing (Scenario FP) is feasible. The current effect of retailer advertising is relatively high, while the current effect of manufacturer advertising can take any value. Thus, the retailer heavily invests in advertising regardless of the level of effectiveness of the manufacturer advertising. Retail prices go up, but remain affordable to ensure profitable transactions in the first period. Channel members realize they can control their advertising expenditures by taking a break in the second period thanks 
mostly to the carryover effects of retailer advertising. Because advertising effects decay exponentially, channel members resume advertising activities in the third period. The carryover effects of the first-period advertising are no longer sufficient to generate enough sales in the third period.

The second intermediate area differs from the first in that the admissible values of the current effect of retailer advertising are lower, but still higher than those in the bottom area and, in addition to Scenario FP, Scenario M is now also feasible. The fact that retailer advertising is less impactful both in the short and long terms leads to smaller investments in retailer advertising in Scenario M. This opens the door for a continuous schedule for retailer advertising to secure profitable sales over time. As in Scenario FP, the manufacturer can still find it optimal to take an advertising break in the second period to benefit from the carryover effects of retailer advertising.

To summarize, the feasibility conditions of Scenarios FC and M imply the fulfillment of those in Scenario FP, which is the only feasible schedule when retailer advertising reaches its highest admissible effectiveness in the short and long terms. The rationale behind this finding is that very impactful retailer advertising campaigns drive retail prices and advertising expenditures up and may erode channel profits. Scenario FP, which allows channel members to take an advertising break in the second period, helps to reduce advertising expenditures and enhances channel profitability over the three periods.

\subsection{Choosing an advertising schedule}

This subsection investigates the conditions under which channel members may implement each of the three advertising schedules identified above. We conduct numerical simulations to compare channel members' profits under the three advertising schedules. The findings of these simulations are summarized in Figure 3. We denote by $M_{i}$ and $R_{i}, i \in\{1,2,3\}$, the region where the manufacturer and retailer respectively earn more profit by implementing the advertising schedule of Scenario $i \in\{F C, F P, M\}$. Again, $U F$ denotes the region where the three advertising schedules are unfeasible.

(Insert Figure 3 about here) 
Given the feasibility conditions as previously illustrated in Figure 2, the manufacturer and retailer implement pulsing (Scenario FP) in the upper part of Figure 3. Of course, the implementation of pulsing when the other two scenarios are not feasible is a channel strategic imperative that allows the two channel members to obtain their best possible profits. As previously discussed, in this context, not only is retailer advertising very effective in the current period, it also significantly impacts the second-period sales. This explains the retailer's choice of a pulsing schedule. Obviously, the manufacturer's choice of a pulsing schedule is not related to the carryover effects of own advertising. It is more attributable to the manufacturer's opportunistic behavior, which allows him to take advantage of the effectiveness of retailer advertising.

On the other hand, when all advertising schedules are simultaneously feasible (Bottom of Figure 3), the two channel members always agree to implement the continuous schedule to cope mainly with the retailer advertising that does not highly impact on current sales and produces relatively small carryover effects. In such a context, the continuous schedule secures higher advertising investments in the three periods than the other two advertising schedules. Any advertising break in the second period hurts channel sales, which already suffer from less effective retailer advertising. Surprisingly, the manufacturer does not select a pulsing schedule even when his own advertising is, respectively, very and relatively effective in the first and second period. In a monopoly context, a pulsing schedule would have been expected to take advantage of the positive carryover effects of own advertising. One possible explanation of the manufacturer's adoption of a continuous schedule in this particular case is his willingness to supplement or support a less effective retailer advertising program.

Finally, in areas where only the feasibility conditions for Scenarios FP and M are met, the two channel members agree to implement Scenario M. The retailer finds it optimal to maintain a continuous advertising schedule, probably because her advertising is moderately effective in the short term and does not carry over enough to compensate an advertising break in subsequent periods. Knowing that, the manufacturer can take a break in the second period even if his own advertising is less effective in both short and long terms. While this situation may not be the best for the retailer, it is still a 
better alternative for her than also to adopt a pulsing schedule, which will result in lower advertising expenditures and lower profits.

\section{Vertically Integrated Vs. Uncoordinated Strategies}

We next investigate how channel strategies compare in the integrated and uncoordinated channels. This is done by conducting numerical simulations for different values of parameters $\alpha, \delta \in(0,1)$. These comparisons are only possible in areas of the parameter space where the two equilibria are feasible. The outcomes of these comparisons are summarized in Proposition 3, where the superscript vi stands for vertical integrated channel and FC and M stand for Scenarios FC and M in the uncoordinated channel.

Proposition 3. (i) With a few exceptions, when the uncoordinated channel implements Scenario FC, the equilibrium strategies compare with the coordinated optimal decisions as follows:

$$
\begin{aligned}
& A_{1}^{v i}>A_{1}^{F C}, \quad A_{2}^{v i}>A_{2}^{F C}, \quad A_{3}^{v i}>A_{3}^{F C}, \\
& a_{1}^{v i}>a_{1}^{F C}, \quad a_{2}^{v i}>a_{2}^{F C}, \quad a_{3}^{v i}>a_{3}^{F C}, \\
& p_{1}^{v i}<p_{1}^{F C}, \quad p_{2}^{v i}<p_{2}^{F C}, \quad p_{3}^{v i}<p_{3}^{F C},
\end{aligned}
$$

(ii) When the uncoordinated channel implements Scenario $M$, the equilibrium strategies compare with the coordinated optimal decisions as follows:

$$
\begin{array}{ll}
A_{1}^{v i}>A_{1}^{M}, & A_{2}^{v i}>A_{2}^{M}, \quad A_{3}^{v i}>A_{3}^{M}, \\
a_{1}^{v i}>a_{1}^{M}, & a_{2}^{v i}>a_{2}^{M}, \quad a_{3}^{v i}>a_{3}^{M}, \\
p_{1}^{v i}>p_{1}^{M}, & p_{2}^{v i}>p_{2}^{M}, \quad p_{3}^{v i}>p_{3}^{M} .
\end{array}
$$

Observe that Scenario FP is left out of this analysis because it is outside the feasibility area of the optimal solution of the integrated channel. The findings of Proposition 3(i) are largely expected. Both retailer and manufacturer advertising expenditures are higher in the integrated channel than when the uncoordinated channel adopts Scenario FC, supporting the existence of advertising free-riding in Scenario FC of the uncoordinated channel. In these two cases, continuous schedules are adopted for the two types of advertising, but the manufacturer and retailer underinvest in advertising in the uncoordinated channel. Retail prices of the uncoordinated channel (Scenario FC) are mostly higher than those of the integrated channel, which also supports the existence of double 
marginalization in pricing. There are, however, a few exceptions for intermediate or high values of $\alpha$ where the above findings on prices do not hold. Examples are

- If $\alpha=0.5$ and $\delta=0.5$, then $p_{1}^{v i}>p_{1}^{F C}, p_{2}^{v i}>p_{2}^{F C}, p_{3}^{v i}>p_{3}^{F C}$.

- If $\alpha=0.75$ and $\delta=0.1$ or $\delta=0.25$, then $p_{1}^{v i}>p_{1}^{F C}, p_{2}^{v i}>p_{2}^{F C}, \quad p_{3}^{v i}>p_{3}^{F C}$.

We have no explanation for these exceptions for which retail prices are higher in the integrated channel than in Scenario FC of the uncoordinated channel.

The comparisons of advertising strategies in Proposition 3 (ii) give expected outcomes. As previously discussed, they support the existence of free-riding in advertising in Scenario $\mathrm{M}$ of the uncoordinated channel as well. Scenario M of the uncoordinated differs, however, from the integrated channel in that a mixed schedule is adopted in the first, while a continuous schedule is optimal in the latter. In such a context, the levels of advertising investments in the second period are very informative. Because the manufacturer does not invest in the second period, the following relationship will always hold: $A_{2}^{v i}>A_{2}^{M}$. Relinquishing advertising investment to the retailer alone in the second period under the pretext that there will be no direct free-riding is not a credible alternative since, $a_{2}^{v i}>a_{2}^{M}$. This is partly explained by the fact that the second-period baseline demand suffers from the limited first-period advertising investments from the two channel partners. Therefore the manufacturer's decision not to invest in the second period in Scenario M cannot be explained by the channel reaching or exceeding the level of advertising investment of the integrated channel.

Pricing comparisons in Proposition 3(ii) give surprising outcomes. Prices are higher in the integrated channel than in the uncoordinated channel when Scenario M is implemented. This goes against the principle of double marginalization, which predicts higher prices in an uncoordinated channel. As just discussed, the manufacturer's decision not to advertise in the second period may lead to this outcome. This decision is opportunistic in the sense that the manufacturer knows there is room to do more advertising, but still decides to take an advertising break in the second period to minimize his advertising expenses, to the detriment of the retailer. In reaction, instead of advertising over her optimal level because of the manufacturer's failure to do advertising in the second period, 
the retailer finds it optimal to reduce retail prices. Because retail prices have a stronger effect on demand than retailer advertising in Scenario M, the retailer will set retail prices at the minimum level possible, which is, in this case, lower than the integrated channel's level.

\section{Conclusion and discussion}

This paper has investigated how channel members, who control their pricing and advertising decisions in a bilateral monopoly context, schedule retailer and manufacturer advertising programs to maximize their profits for a planning horizon of three periods. The analysis of a vertically integrated channel where a single decision maker has the possibility of undertaking retailer and manufacturer advertising reveals that continuous schedules should be adopted for these two types of advertising when their effects are not very large in the current period and decay exponentially over time.

The findings of the uncoordinated channel where the manufacturer and retailer set their decisions to maximize their respective profits over the three periods are less straightforward. Depending on the effects of retailer and manufacturer advertising, the full continuous, full pulsing, and mix schedules are feasible at the equilibrium. Full pulsing is the only feasible schedule when retailer advertising is very impactful. However, when the full continuous and the mix schedule are also feasible, the two channel members always prefer the full continuous schedule to the mix schedule, which is also preferred to the full pulsing schedule. This occurs particularly when the effects of retailer advertising are not very large in both the short and long terms.

The findings of this research have four major theoretical and managerial implications. First, previous research in advertising scheduling has theorized, in the case of a single advertiser, that a pulsing schedule is preferable to a continuous schedule when advertising decays slowly over time (Ephron and McDonald, 2002). The argument holds that advertising should only be done on a continuous basis when it does not carry over enough to subsequent periods to ensure the same level of effectiveness over time if periodical breaks are taken within the planning horizon. Some of our findings are consistent with this previous literature. Particularly, we found that, in a vertically integrated channel, in which 
advertising generates small and moderate effects that decay exponentially over time, the full continuous schedule should be adopted.

Second, unlike in any previous work, we show that the presence or absence of large carryover effects at the manufacturer's level alone cannot explain the use of any single advertising schedule in a conventional channel. This finding is explained by the fact that, in a conventional channel in which both the manufacturer and retailer advertise, advertising creates two non-trivial issues that do not exist in a vertically integrated channel or in a single monopoly. The first is the existence of vertical externalities, including freeriding, which can prevent a channel member from investing in advertising or can lead to suboptimal advertising investments. As a matter of fact, our findings show that the manufacturer can take an advertising break in the second period just to benefit from a very effective retailer advertising program (Scenarios FP and M); this is possible even when his own advertising does not generate any substantial carryover effect. The second issue is the understanding of the long-term effects of both retailer and manufacturer advertising on sales. For instance, the first-period manufacturer advertising may not stimulate enough sales in the second period to justify a stop of retailer advertising in that period if the retailer main advertising goal is to increase current sales. This is often the case when retailers want to clear unwanted stocks or maximize seasonal sales by investing in promotional advertising activities. The implementation of each of the three equilibrium advertising schedules in a conventional channel should therefore effectively cope with these two issues.

Third, some advertising schedules in conventional channels may drive prices down to levels inferior to integrated channel prices (because of the double marginalization phenomenon, conventional channel prices are expected to be higher). This surprising result is more likely to happen when retailer advertising is relatively effective, so a manufacturer, in a leadership position, can find it optimal to periodically stop his own advertising. This does not, however, translate into a more effective conventional channel, as the integrated channel profit remains higher. This means that the retailer gives away part of her margin to stimulate more sales as a response to the manufacturer's failure to advertise continuously. 
Finally, because consumer sensitivity to retail prices and advertising for products that are used on an ongoing basis does not significantly change over time, continuous advertising schedules are generally believed to be suitable for this type of product. The theory developed in this paper shows that this may not always be the case. Advertising carryover effects and vertical externalities are other relevant factors to consider. Therefore, manufacturers and retailers should adapt their advertising schedules to the characteristics of their specific advertising programs.

A simple model was analyzed in this paper to derive meaningful insights that can shed some light in this area and inspire future research. Several extensions of this model are possible. For instance, consumer sensitivity to retail prices and promotional activities can change over time. In a more general specification, different and independent parameters for the short-term and long-term effects of each type of advertising can be considered. Also, because our model is dynamic, one can consider that previous prices affect current sales. Interactions between retailer and manufacturer advertising can be added. Instead of linear demand functions, other demand functions can be considered. Budget constraints can be introduced. Situations where there is no leader in the channel or the retailer is the Stackelberg leader can be investigated.

\section{References:}

[1] Aravindakshan, A., \& Naik, P. A. (2011). How does awareness evolve when advertising stops? The role of memory. Marketing Letters, 22, 315-326.

[2] Aust, G., \& Buscher, U. (2014). Cooperative advertising models in supply chain management: A review. European Journal of Operational Research, 234, 1-14.

[3] Barkholz, D. (2015). Toyota tells dealers that below-invoice ads are taboo. Automotive News, September 10. Retrieved on March 11, 2016 at: http://www.autonews.com/article/20150910/RETAIL07/150919980?template=printart

[4] Belch, E. G, Belch, M. A., \& Guolla, M. A. (2014). Advertising $\& 3$ Promotion. (5th Canadian Edition). McGraw-Hill Ryerson. 
[5] Breuer, R., Brettel, M., \& Engelen, A. (2011). Incorporating long-term effects in determining the effectiveness of different types of online advertising. Marketing Letters, $22,327-340$.

[6] DelVecchio, D., Henard, D. H., \& Freling, T. H. (2006). The effect of sales promotion on post-promotion brand preference: A meta-analysis. Journal of Retailing, 82(3), 203-213.

[7] Dubé, J-. P., Hitsch, G. J., \& Manchanda, P. (2005). An empirical model of advertising dynamics. Quantitative Marketing and Economics, 3, 107-144.

[8] Ephron, E., \& McDonald, C. (2002). Media scheduling and carry-over effects: Is Adstock a useful TV planning tool? Journal of Advertising Research, July-August, $66-70$.

[9] Freimer, M. \& Horsky, D. (2012). Periodic advertising pulsing in a competitive market. Marketing Science, 637-648.

[10] Herrington, J. D., \& Dempsey, W. A. (2005). Comparing the current effects and carryover of national-, regional-, and local-sponsor advertising. Journal of Advertising Research, March, 60-72.

[11] Jørgensen, S., Sigué, S. P., \& Zaccour, G. (2000). Dynamic cooperative advertising in a marketing channel. Journal of Retailing, 76, 71-92.

[12] Jørgensen, S., Sigué, S. P., \& Zaccour, G. (2001). Stackelberg leadership in a marketing channel. International Game Theory Review, 3(1), 1-14.

[13] Jørgensen, S., Taboubi, S., \& Zaccour, G. (2003). Retail promotions with negative brand image effects: Is cooperation possible? European Journal of Operational Research, 150, 395-405.

[14] Jørgensen, S., \& Zaccour, G. (2014). A survey of game-theoretic models of cooperative advertising. European Journal of Operational Research, 237, 1-14. 
[15] Kantar Media. (2014). Kantar Media Reports U.S. Advertising Expenditures. Retrieved September 17, 2014 from http://content.kantarmedia.fr/KantarMediaQ12014USAdSpend.pdf.

[16] Karray, S. (2013). Periodicity of pricing and marketing efforts in a distribution channel. European Journal of Operational Research, 228, 635-647.

[17] Karray, S., \& Zaccour, G. (2006). Could co-op advertising be a manufacturer's counterstrategy to store brands? Journal of Business Research, 59, 1008-1015.

[18] Mahajan, V., \& Muller, E. (1986). Advertising pulsing policies for generating awareness for new products. Marketing Science, 5(2), 89-106.

[19] Martín-Herrán, G., Sigué, S. P. (2017). An integrative framework of cooperative advertising: Should manufacturers continuously support retailer advertising? Journal of Business Research, 70, 67-73.

[20] Martín-Herrán, G., Sigué, S. P., \& Zaccour, G. (2010). The dilemma of pull and push-price promotions. Journal of Retailing, 86(1), 51-68.

[21] Mesak, H. I., \& Ellis, T. S. (2009). On the superiority of pulsing under a concave advertising market potential function. European Journal of Operational Research, $194,608-627$.

[22] Sasieni. M. W. (1989). Optimal advertising strategies. Marketing Science, 8(4), 358370.

[23] Sigué, S. P. (2008). Consumer and retailer promotions: Who is better off? Journal of Retailing, 84(4), 449-460.

[24] Sigué, S. P., \& Chintagunta, P. (2009). Advertising strategies in a franchise system. European Journal of Operational Research, 198 (2), 655-665.

[25] Szmerekovsky, J.G., \& Zhang, J. (2009). Pricing and two-tier advertising with one manufacturer and one retailer. European Journal of Operational Research, 192, 904917. 
[26] Villas-Boas, J. M. (1993). Predicting advertising pulsing policies in an oligopoly: A model and empirical test. Marketing Science, 12(1), 88-102.

[27] Wolfram Research, Inc. (2014). Mathematica Edition: Version 10.0.2.0 Wolfram Research, Inc. Champaign, Illinois.

[28] Xie, J., \& Ai, S. (2006). A note on "cooperative advertising, game theory and manufacturer-retailer supply chains". Omega, 34, 501-504.

[29] Yan, R. (2010). Cooperative advertising, pricing and firm performance in the emarketing age. Journal of the Academy of Marketing Science, 38, 510-519.

[30] Zhang, J., Gou, Q., Liang, L., \& Huang, Z. (2013). Supply chain coordination through cooperative advertising with reference price effect. Omega, 41, 345-353. 
Table 1: Model specifications

\begin{tabular}{|l|c|c|c|}
\hline & Period 1 & Period 2 & Period 3 \\
\hline Manufacturer's controls & $w_{1}, A_{1}$ & $w_{2}, A_{2}$ & $w_{3}, A_{3}$ \\
Retailer's controls & $p_{1}, a_{1}$ & $p_{2}, a_{2}$ & \\
& & & $p_{3}$ \\
Demand functions & $q_{1}=g-p_{1}+\delta a_{1}+\alpha A_{1}$ & $q_{2}=g-p_{2}+\delta a_{2}+\alpha A_{2}$ & $q_{3}=g-p_{3}+\delta a_{3}+\alpha A_{3}$ \\
& & $+\delta^{2} a_{1}+\alpha^{2} A_{1}$ & $+\delta^{2} a_{2}+\alpha^{2} A_{2}+\delta^{3} a_{1}+\alpha^{3} A_{1}$ \\
Manufacturer's profits & $M_{1}=w_{1} q_{1}-\frac{1}{2} A_{1}^{2}$ & $M_{2}=w_{2} q_{2}-\frac{1}{2} A_{2}^{2}$ & $M_{3}=w_{3} q_{3}-\frac{1}{2} A_{3}^{2}$ \\
Retailer's profits & $R_{1}=\left(p_{1}-w_{1}\right) q_{1}-\frac{1}{2} a_{1}^{2}$ & $R_{2}=\left(p_{2}-w_{2}\right) q_{2}-\frac{1}{2} a_{2}^{2}$ & $R_{3}=\left(p_{3}-w_{3}\right) q_{3}-\frac{1}{2} a_{3}^{2}$ \\
\hline
\end{tabular}


Table 2: Optimal advertising schedules

\begin{tabular}{|l|c|c|c|}
\hline & \multicolumn{1}{|c|}{ 1st period } & 2nd period & 3rd period \\
\hline Full continuous (Scenario FC) & $a_{1}^{F C}>0, A_{1}^{F C}>0$ & $a_{2}^{F C}>0, A_{2}^{F C}>0$ & $a_{3}^{F C}>0, A_{3}^{F C}>0$ \\
\hline Full pulsing (Scenario FP) & $a_{1}^{F P}>0, A_{1}^{F P}>0$ & $a_{2}^{F P}=0, A_{2}^{F P}=0$ & $a_{3}^{F P}>0, A_{3}^{F P}>0$ \\
\hline Mixed (Scenario M) & $a_{1}^{M}>0, A_{1}^{M}>0$ & $a_{2}^{M}>0, A_{2}^{M}=0$ & $a_{3}^{M}>0, A_{3}^{M}>0$ \\
\hline
\end{tabular}




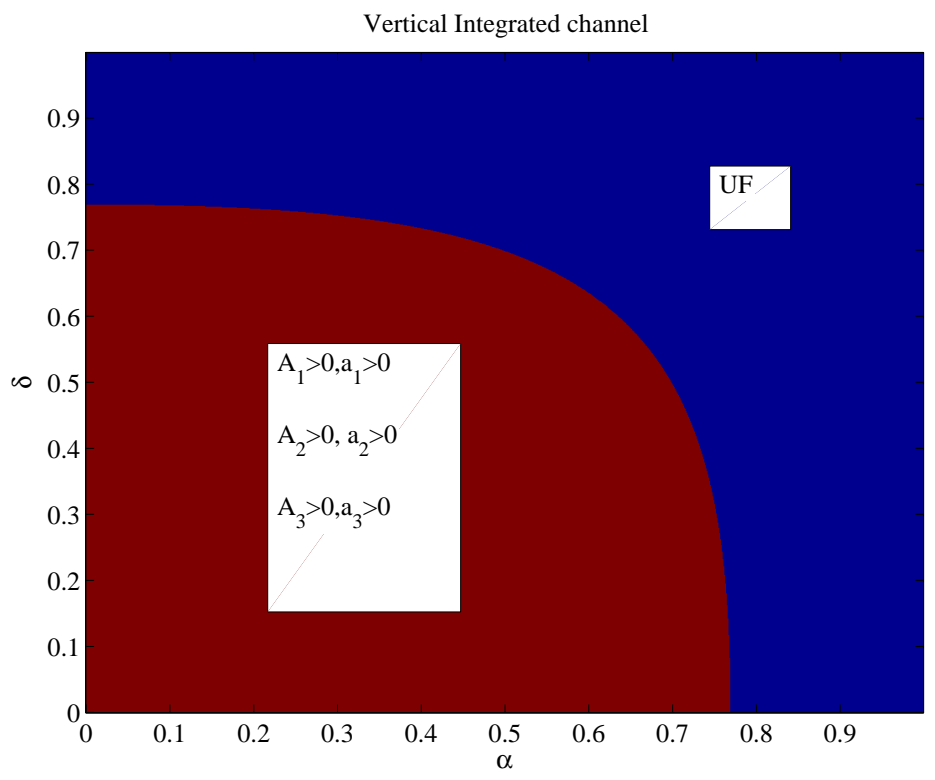

Figure 1: Vertical integrated channel 


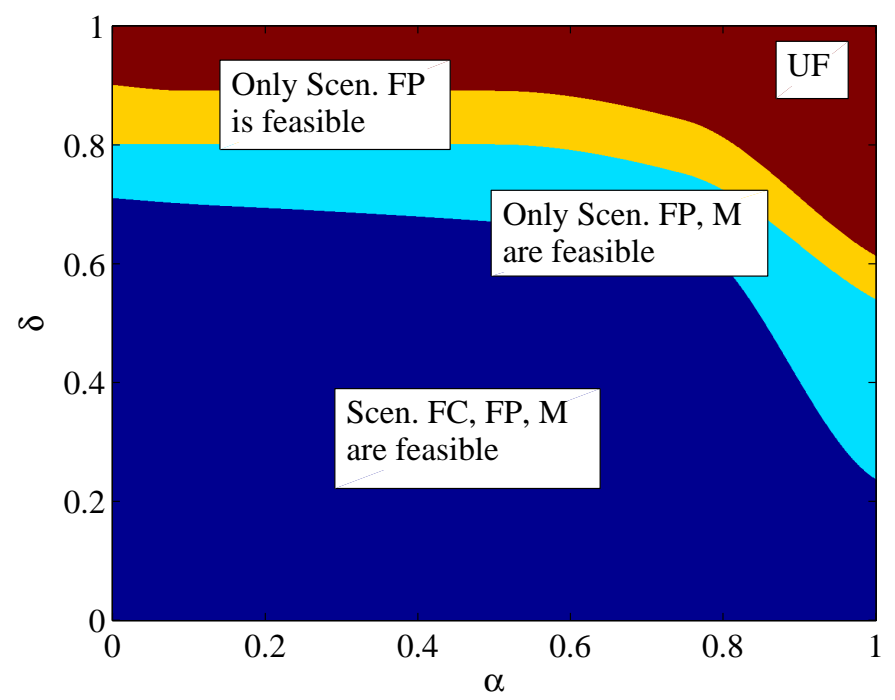

Figure 2: Feasible and unfeasible regions for Scenarios FC, FP and M 


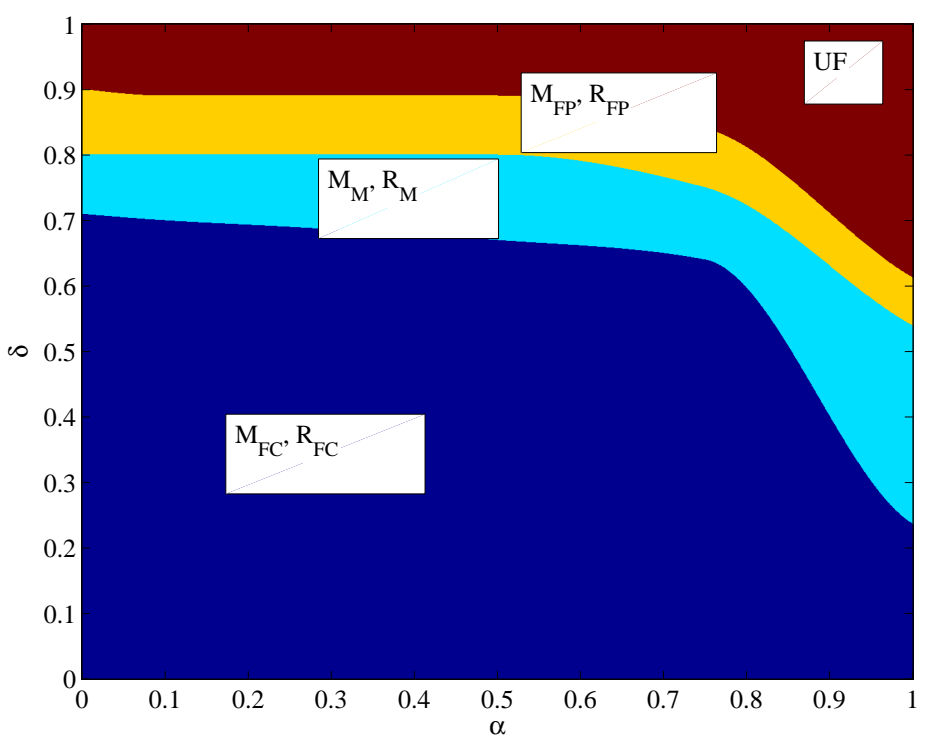

Figure 3: Equilibria 